\title{
Golimumab in patients with active rheumatoid arthritis who have previous experience with tumour necrosis factor inhibitors: results of a long-term extension of the randomised, double-blind, placebo-controlled GO-AFTER study through week 160
}

\author{
Josef S Smolen, ${ }^{1}$ Jonathan Kay, ${ }^{2}$ Robert B M Landewé, ${ }^{3}$ Eric L Matteson, ${ }^{4}$ \\ Norman Gaylis, ${ }^{5}$ Jurgen Wollenhaupt, ${ }^{6}$ Frederick T Murphy, ${ }^{7}$ Yiying Zhou, ${ }^{8}$ \\ Elizabeth C Hsia, ${ }^{9,10}$ Mittie K Doyle 9,10
}

- An additional table is published online only. To view these files, please visit the journal online (http://dx.doi.org/10.1136/ annrheumdis-2011-200956)

${ }^{1}$ Department of Rheumatology, Department of Medicine 3,

Medical University of Vienna, and $2^{\text {nd }}$ Department of Medicine, Hietzing Hospital, Vienna, Austria 2Department of Medicine,

UMass Memorial Medical Center, Worcester, Massachusetts, USA ${ }^{3}$ Department of Rheumatology, AVU Amsterdam, Amsterdam, Netherlands

${ }^{4}$ Department of Rheumatology, Mayo Clinic, Rochester

Minnesota, USA

${ }^{5}$ Department of Arthritis and

Rheumatic Disease Specialties,

Aventura, Florida, USA

${ }^{6}$ Department of Rheumatology,

Klinik Eibek, Hamburg, Germany

${ }^{7}$ Department of Rheumatology,

Altoona Center of Clinical

Research, Duncansville,

Pennsylvania, USA

${ }^{8}$ Department of Biostatistics,

Janssen Research \&

Development, LLC, Spring

House, Pennsylvania, USA

${ }^{9}$ Department of Immunology,

Janssen Research \&

Development, LLC, Spring

House, Pennsylvania, USA

${ }^{10}$ University of Pennsylvania

Medical School, Philadelphia,

PA, USA

\section{Correspondence to}

Josef S Smolen, Medical

University of Vienna, Department of Rheumatology, Vienna, Austria; josef.smolen@wienkav.at

Received 24 October 2011 Accepted 31 January 2012

\section{UNIOCKID}

This paper is freely available online under the BMJ Journals unlocked scheme, see http:// ard.bmj.com/info/unlocked.dtl

\section{ABSTRACT}

Objective The aim of this study was to assess long-term golimumab therapy in patients with rheumatoid arthritis (RA) who discontinued previous tumour necrosis factor alpha (TNF $\alpha$ ) inhibitor(s) for any reason.

Methods Results through week 24 of this multicentre, randomised, double-blind, placebo-controlled study of active RA ( $\geq 4$ tender, $\geq 4$ swollen joints) were previously reported. Patients received placebo (Group 1), 50 mg golimumab (Group 2) or 100 mg golimumab (Group 3) subcutaneous injections every 4 weeks. Patients from Groups 1 and 2 with $<20 \%$ improvement in tender/swollen joints at week 16 early escaped to golimumab $50 \mathrm{mg}$ and $100 \mathrm{mg}$, respectively. At week 24, Group 1 patients crossed over to golimumab $50 \mathrm{mg}$ Group 2 continued golimumab 50/100 mg per escape status and Group 3 maintained dosing. Data through week 160 are reported.

Results 459 of the 461 randomised patients were treated; 236/459 (51\%) continued treatment through week 160. From week 24 to week 100, ACR20 ( $\geq 20 \%$ improvement in American College of Rheumatology criteria) response and $\geq 0.25$ unit $\mathrm{HAO}$ (Health Assessment Questionnaire) improvement were sustained in $70-73 \%$ and $75-81 \%$ of responding patients, respectively. Overall at week $160,63 \%, 67 \%$ and $57 \%$ of patients achieved ACR20 response and 59\%, 65\% and $64 \%$ had HAO improvement $\geq 0.25$ unit in Groups 1, 2 and 3 , respectively. Adjusted for follow-up duration, adverse event incidences (95\% Cl) per 100 patient-years among patients treated with golimumab $50 \mathrm{mg}$ and $100 \mathrm{mg}$ were 4.70 (2.63 to 7.75) and 8.07 (6.02 to 10.58) for serious infection, 0.95 (0.20 to 2.77) and 2.04 (1.09 to 3.49) for malignancy and $0.00(0.00$ to 0.94$)$ and $0.62(0.17$ to 1.59) for death, respectively.

Conclusion In patients with active RA who discontinued previous TNF-antagonist treatment, golimumab 50 and 100 mg injections every 4 weeks yielded sustained improvements in signs/symptoms and physical function in $~ 57-67 \%$ of patients who continued treatment. Golimumab safety was consistent with other anti-TNF agents, although definitive conclusions regarding long-term safety require further monitoring.
Tumour necrosis factor alpha (TNF $\alpha$ ) inhibitors have been used to treat rheumatoid arthritis (RA) for $>10$ years. Patients with insufficient response to TNF inhibitors are routinely switched to other biological agents, including other TNF inhibitors. Thus, increasingly more patients with RA have previous experience with $\geq 1 \mathrm{TNF}$ inhibitor. Among the newer anti-TNF agents, golimumab is a human monoclonal anti-TNF agent administered subcutaneously every 4 weeks.

GO-AFTER (GOlimumab After Former antitumour necrosis factor $\alpha$ Therapy Evaluated in Rheumatoid arthritis) was the first prospective, randomised, phase 3, double-blind, placebo-controlled trial to assess a TNF inhibitor in patients with active RA who previously received TNF inhibitor(s). These patients had also received several disease-modifying antirheumatic drugs (DMARDs) prior to TNF inhibitor(s), thereby representing a difficult-to-treat population. Treatment with golimumab $50 \mathrm{mg}$ and $100 \mathrm{mg}$ every 4 weeks versus placebo yielded significantly higher ACR20 ( $\geq 20 \%$ improvement in American College of Rheumatology criteria) response rates at week 14 (35\% and $38 \%$ vs $18 \%$, respectively; both $\mathrm{p}<0.001)$ and no unexpected safety concerns through week $24 .{ }^{1}$ Efficacy and safety findings through week 160 of the GO-AFTER long-term extension (LTE) are reported herein.

\section{PATIENTS AND METHODS}

GO-AFTER (NCT00299546) was conducted according to the Declaration of Helsinki. All patients provided written informed consent, and the protocol was approved by each institution's human subjects ethical review board.

\section{Patients}

Patient enrolment began 21 February 2006; data were collected at visits conducted through LTE week 160 . Eligible patients with $\mathrm{RA}^{2}$ had active disease ( $\geq 4$ swollen, $\geq 4$ tender joints); had previously received etanercept, adalimumab or infliximab for $\geq 8$ (adalimumab, etanercept) or $\geq 12$ (infliximab) 


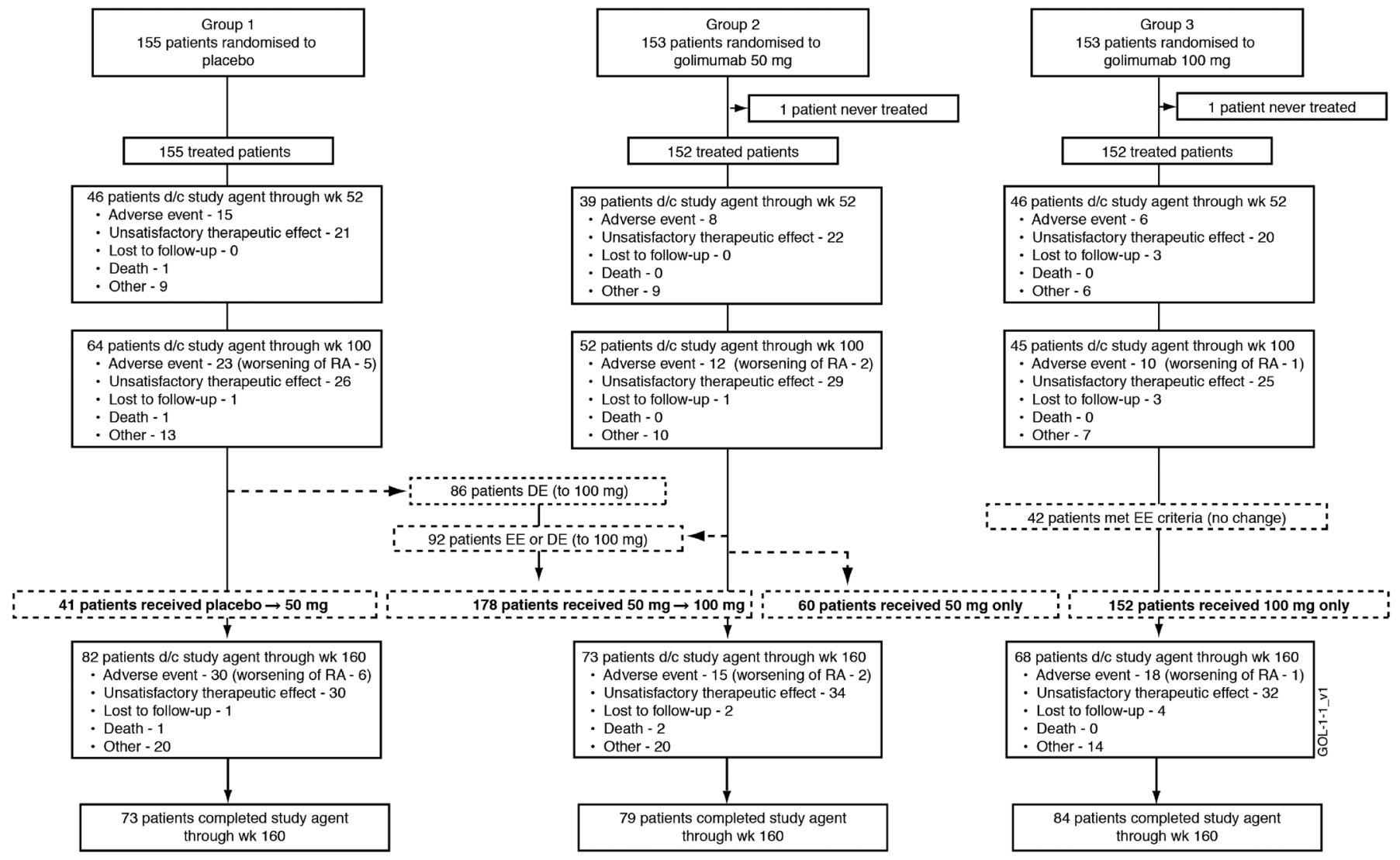

$\mathrm{d} / \mathrm{c}=$ discontinued $; \mathrm{DE}=$ dose escalate $; \mathrm{EE}=$ early escaped $\mathrm{RA}=$ rheumatoid arthritis; $w \mathrm{k}=$ week

Figure 1 Patient disposition through week 160.

weeks; and could have discontinued these agents for any reason (documented as lack of efficacy, intolerance, other). Additional inclusion/exclusion criteria were previously reported. ${ }^{1}$

\section{Study design}

Patients were randomised (1:1:1) to receive subcutaneous injections of placebo, golimumab $50 \mathrm{mg}$ or golimumab $100 \mathrm{mg}$ every 4 weeks. Stable doses of synthetic DMARDs were allowed. Patients and investigators were blinded to treatment assignment; golimumab and placebo were supplied in identical singleuse vials.

Patients in the placebo and golimumab $50 \mathrm{mg}$ groups with $<20 \%$ improvement in both tender and swollen joint counts at week 16 early escaped (EE) to receive golimumab $50 \mathrm{mg}$ or $100 \mathrm{mg}$, respectively, at week 16 and week 20. Dosing was not changed in the $100 \mathrm{mg}$ group.

GO-AFTER included a LTE. From week 24 forward, patients in the placebo group crossed over to golimumab $50 \mathrm{mg}$ every 4 weeks and patients in the golimumab $50 \mathrm{mg}$ group continued with golimumab 50 or 100 mg every 4 weeks per EE status. The study blind was maintained during the LTE until the week 24 database lock, after which patients receiving golimumab 50 mg could escalate to $100 \mathrm{mg}$ at the investigator's discretion. Golimumab doses could not be reduced through week 160 .

\section{Procedures}

Clinical response through week 160 was assessed using ACR20/50/70, ${ }^{3}$ 28-joint count Disease Activity Score (DAS28) response (good/moderate) and DAS28 remission (score $<2.6$ ) criteria. ${ }^{4-6}$ DAS28 scores were determined using erythrocyte sedimentation rate (ESR) and $C$ reactive protein (CRP) with established cut points for disease activity states. ${ }^{7}$ Clinical remission according to ACR-EULAR (European League Against Rheumatism) criteria was also evaluated using the Simplified Disease Activity Index (SDAI score $\leq 3.3) .{ }^{89}$ Physical function was assessed using the Health Assessment Questionnaire (HAQ). ${ }^{10}$ Adverse events (AEs) were coded according to MedDRA. ${ }^{1}$

\section{Data analysis}

Clinical outcomes through week 160 are summarised as observed data by randomised treatment groups using descriptive statistics; missing data were neither replaced nor imputed. All patients remaining in the study, including those initially treated with placebo, received golimumab for $\geq 2$ years by week 160 , precluding statistical comparisons among treatment groups. The proportions of patients achieving ACR response, DAS28 response/remission, ACR-EULAR index remission (SDAI) remission and/or $\geq 0.25$ unit improvement in $\mathrm{HAQ}^{11}$ were determined. Changes from baseline (week 0 of main study) were also determined. Treatment groups were defined according to patients' original randomisation: (1) patients randomised to placebo, including patients who EE at week 16 or crossed over at week 24 to golimumab $50 \mathrm{mg}$ and/or escalated after week 24 to $100 \mathrm{mg}$; (2) patients randomised to golimumab $50 \mathrm{mg}$, including patients who EE at week 16 or dose escalated after week 24 to $100 \mathrm{mg}$; and (3) patients randomised to golimumab 100 mg. Efficacy data from one North American site (16 patients) were excluded because of protocol violations identified during 
Table 1 Summary of patient characteristics and RA medications at baseline of the GO-AFTER trial

\begin{tabular}{|c|c|c|c|}
\hline & Placebo* & Golimumab 50 mgt & Golimumab 100 mg \\
\hline Number of randomised patients & 155 & 153 & 153 \\
\hline Female & $132(85.2 \%)$ & $113(73.9 \%)$ & $122(79.7 \%)$ \\
\hline Age & $54.8 \pm 13.07(54.0)$ & $53.9 \pm 11.47(55.0)$ & $53.7 \pm 12.26(55.0)$ \\
\hline Disease duration (years) & $12.4 \pm 9.58(9.8)$ & $12.4 \pm 9.24(9.6)$ & $10.6 \pm 7.90(8.7)$ \\
\hline CRP (mg/dl) & $2.1 \pm 3.16(1.0)$ & $2.2 \pm 2.97(0.8)$ & $2.1 \pm 3.38(0.8)$ \\
\hline $\mathrm{ESR}(\mathrm{mm} / \mathrm{h})$ & $38.4 \pm 26.27(32.0)$ & $35.2 \pm 26.98(27.5)$ & $37.9 \pm 29.92(30.0)$ \\
\hline Number of swollen joints $(0-66)$ & $17.5 \pm 11.76(14.0)$ & $17.8 \pm 11.82(14.0)$ & $15.4 \pm 9.49(13.0)$ \\
\hline Number of tender joints $(0-68)$ & $30.0 \pm 17.56(26.0)$ & $30.6 \pm 16.86(27.0)$ & $29.1 \pm 16.69(26.0)$ \\
\hline HAO score $(0-3)$ & $1.6 \pm 0.6(1.8)$ & $1.6 \pm 0.7(1.60)$ & $1.5 \pm 0.6(1.5)$ \\
\hline DAS28-ESR score (0-10) & $6.2 \pm 1.19(6.3)$ & $6.3 \pm 1.25(6.3)$ & $6.1 \pm 1.24(6.1)$ \\
\hline DAS28-CRP score (0-10) & $5.1 \pm 0.99(5.1)$ & $5.3 \pm 1.05(5.4)$ & $5.1 \pm 0.92(5.1)$ \\
\hline SDAI score $(0-100)$ & $40.9 \pm 14.59(38.4)$ & $43.2 \pm 15.89(42.1)$ & $40.7 \pm 13.88(40.3)$ \\
\hline Previous anti-TNF for RA & $155(100.0 \%)$ & $153(100.0 \%)$ & $153(100.0 \%)$ \\
\hline Adalimumab, by reason for $\mathrm{d} / \mathrm{c}$ & $85(54.8 \%)$ & 72 (47.1\%) & 65 (42.5\%) \\
\hline Lack of efficacy & $53(34.2 \%)$ & $44(28.8 \%)$ & $40(26.1 \%)$ \\
\hline Intolerance & $3(1.9 \%)$ & $9(5.9 \%)$ & $10(6.5 \%)$ \\
\hline Other & $29(18.7 \%)$ & $19(12.4 \%)$ & $15(9.8 \%)$ \\
\hline Etanercept, by reason for $\mathrm{d} / \mathrm{c}$ & $73(47.1 \%)$ & $76(49.7 \%)$ & $73(47.7 \%)$ \\
\hline Lack of efficacy & $40(25.8 \%)$ & $49(32.0 \%)$ & $40(26.1 \%)$ \\
\hline Intolerance & $11(7.1 \%)$ & $4(2.6 \%)$ & $10(6.5 \%)$ \\
\hline Other & $22(14.2 \%)$ & $23(15.0 \%)$ & $23(15.0 \%)$ \\
\hline Infliximab, by reason for $\mathrm{d} / \mathrm{c}$ & $83(53.5 \%)$ & $64(41.8 \%)$ & $71(46.4 \%)$ \\
\hline Lack of efficacy & $48(31.0 \%)$ & $33(21.6 \%)$ & $36(23.5 \%)$ \\
\hline Intolerance & $14(9.0 \%)$ & $9(5.9 \%)$ & $16(10.5 \%)$ \\
\hline Other & $21(13.5 \%)$ & $22(14.4 \%)$ & $19(12.4 \%)$ \\
\hline \multirow[t]{3}{*}{ Methotrexate use at baseline } & $102(65.8 \%)$ & $103(67.8 \%)$ & $100(65.8 \%)$ \\
\hline & \multicolumn{3}{|c|}{ Number of previous anti-TNF agents $\ddagger$} \\
\hline & 1 previous anti-TNF $(n=292)$ & 2 previous anti-TNFs $(n=113)$ & 3 previous anti-TNFs $(n=40)$ \\
\hline \multicolumn{4}{|l|}{ Reason for $\mathrm{d} / \mathrm{c}$ through week 160} \\
\hline $\mathrm{AE}$ & $34(11.6 \%)$ & $18(15.9 \%)$ & $11(27.5 \%)$ \\
\hline Death & $3(1.0 \%)$ & $0(0.0 \%)$ & $0(0.0 \%)$ \\
\hline Lost to follow-up & $5(1.7 \%)$ & $2(1.8 \%)$ & $0(0.0 \%)$ \\
\hline Other & $33(11.3 \%)$ & $9(8.0 \%)$ & $2(5.0 \%)$ \\
\hline Unsatisfactory therapeutic effect & $48(16.4 \%)$ & $29(25.7 \%)$ & $15(37.5 \%)$ \\
\hline
\end{tabular}

Data presented are mean \pm SD (median) or number (\%) of randomised patients.

*Includes patients who EE at week 16 or crossed over at week 24 to receive golimumab 50 mg or dose escalated after the week 24 database lock to receive golimumab 100 mg. tIncludes patients who EE at week 16 or dose escalated after the week 24 database lock to receive golimumab $100 \mathrm{mg}$.

$\ddagger$ Based on the 445 patients included in efficacy analyses after exclusion of 16 patients at one study site.

$A E$, adverse event; CRP, $C$ reactive protein; DAS, Disease Activity Score; $d / c$, discontinuation; $E E$, early escaped; ESR, erythrocyte sedimentation rate; HAQ, Health Assessment Questionnaire; RA, rheumatoid arthritis; SDAI, Simplified Disease Activity Index; TNF, tumour necrosis factor.

standard auditing; baseline and safety data from these patients were included. Because numbers of patients in LTE phases of double-blind trials typically decline over time, thereby yielding falsely elevated response rates among the remaining responderenriched population, ${ }^{12}$ efficacy data are presented as (1) absolute numbers to demonstrate actual changes observed during the LTE, despite the limited numbers of patients with response data, and (2) proportions of responders based on randomised patients who continued study participation and had response data, despite the enriched nature of the resulting population.

Safety data are summarised for randomised and treated patients. Individual AEs were attributed to treatment received at onset; therefore, individual patients may appear in $>1$ treatment column. Standardised incidence ratios (SIRs) for malignancies were determined using the Surveillance, Epidemiology and End Results (SEER) database. ${ }^{13}$

\section{RESULTS}

\section{Patient disposition and characteristics}

Patient recruitment began in February 2006, and data included in this report were collected through study week 160. Patient disposition through week 24 has been detailed. Overall, 57 of $461(12.4 \%)$ randomised patients discontinued study participation through week 24 , including $31 / 155$ (20.0\%), 12/153 $(7.8 \%)$ and $14 / 153(9.2 \%)$ patients randomised to receive placebo, golimumab $50 \mathrm{mg}$ and golimumab $100 \mathrm{mg}$, respectively. ${ }^{1}$ Approximately one-half of treated patients continued study treatment through week 160 (figure 1). Common reasons for study agent discontinuation included unsatisfactory therapeutic effect ( $43 \%$ of discontinued patients) and AEs (28\%, including nine patients with worsening RA) (figure 1). The proportions of patients discontinuing study agent due to AEs or unsatisfactory therapeutic effect increased with greater number of previous TNF antagonists (table 1).

The extent of active disease, inflammation and physical function impairment and reasons for previous TNF inhibitor(s) discontinuation were consistent across treatment groups (table 1). Overall, 178 patients dose escalated $(50 \rightarrow 100 \mathrm{mg})$ at the investigator's discretion. During the LTE, 70\% (137/195) of eligible patients dose escalated (figure 1).

\section{Clinical response}

The proportions of patients achieving ACR20, DAS28-ESR response and DAS28-ESR remission at week 24 among patients 
Table 2 Summary of clinical response to golimumab at weeks 52,100 and 160 of the GO-AFTER trial

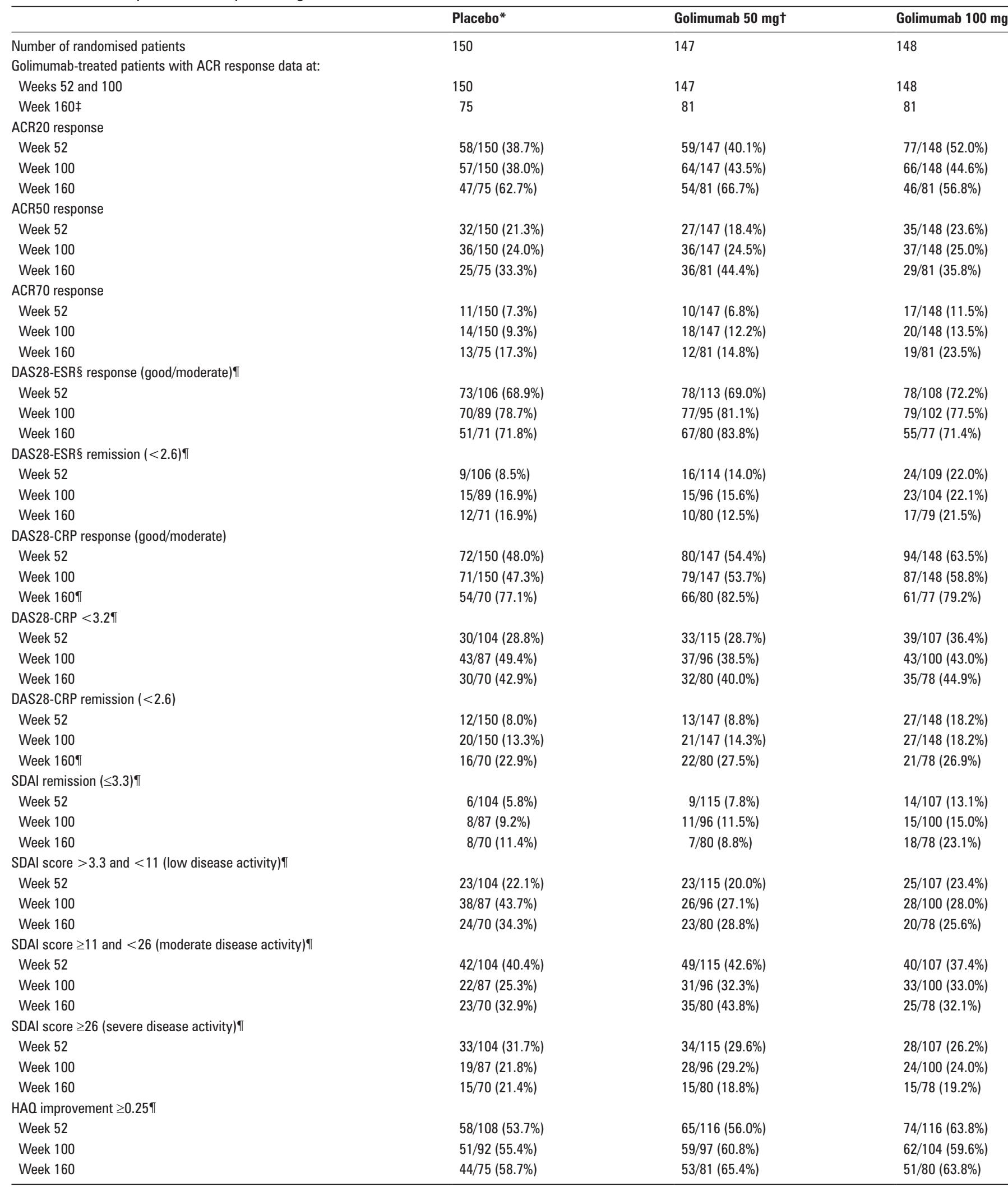

Data presented are median (interquartile range) or number (\%) of randomised patients. Efficacy data pertaining to 16 patients $(5,6$ and 5 patients randomised to placebo, golimumab 50 $\mathrm{mg}$ and golimumab $100 \mathrm{mg}$, respectively) at site 7465 were excluded due to violations at the study site identified during the sponsor's standard audit processes.

* Includes patients who EE at week 16 or crossed over at week 24 to receive golimumab $50 \mathrm{mg}$ or dose escalated after the week 24 database lock to receive golimumab 100 mg.

tIncludes patients who EE at week 16 or dose escalated after the week 24 database lock to receive golimumab $100 \mathrm{mg}$.

fBy week 160, only 75, 81 and 81 patients had ACR response data in Groups 1, 2 and 3, respectively.

$\S E S R$ determinations were not available for all patients at all time points; therefore, DAS28-ESR scores were determined in fewer patients.

TAnalysis based on observed data.

ACR, American College of Rheumatology; CRP, C reactive protein; DAS, Disease Activity Score; EE, early escaped; ESR, erythrocyte sedimentation rate; HAQ, Health Assessment Questionnaire; SDAI, Simplified Disease Activity Index. 
Table 3 Sustained clinical response to golimumab in the GO-AFTER trial

\begin{tabular}{|c|c|c|c|}
\hline & Placebo* & Golimumab 50 mg $\dagger$ & $\begin{array}{l}\text { Golimumab } 100 \\
\text { mg }\end{array}$ \\
\hline Number of randomised patients & 150 & 147 & 148 \\
\hline \multicolumn{4}{|l|}{ Golimumab-treated patients with response data at: } \\
\hline Weeks 52 and 100 & 150 & 147 & 148 \\
\hline Week $160 \ddagger$ & 75 & 81 & 81 \\
\hline ACR20 response at both week 24 and week $100 \S \mathbb{I}$ & & $38 / 54(70.4 \%)$ & $40 / 55(72.7 \%)$ \\
\hline \multicolumn{4}{|l|}{$\begin{array}{l}\text { ACR20 response relative to dose escalation }(50 \rightarrow 100 \mathrm{mg}) \\
\text { among patients with ample data } \uparrow\end{array}$} \\
\hline Previous to dose escalation & & \multicolumn{2}{|c|}{$43 / 117(36.8 \%)$} \\
\hline 12 weeks after dose escalation & & \multicolumn{2}{|c|}{$48 / 100(48.0 \%)$} \\
\hline 24 weeks after dose escalation & & \multicolumn{2}{|c|}{$36 / 69(52.2 \%)$} \\
\hline ACR50 response at both week 24 and week $100 \S \uparrow$ & & $20 / 25(80.0 \%)$ & $15 / 26(57.7 \%)$ \\
\hline \multicolumn{4}{|l|}{$\begin{array}{l}\text { ACR50 response relative to dose escalation }(50 \rightarrow 100 \mathrm{mg}) \\
\text { among patients with ample data }\end{array}$} \\
\hline Previous to dose escalation & & \multicolumn{2}{|c|}{$9 / 117(7.7 \%)$} \\
\hline 12 weeks after dose escalation & & \multicolumn{2}{|c|}{$21 / 100(21.0 \%)$} \\
\hline 24 weeks after dose escalation & & \multicolumn{2}{|c|}{$18 / 69(26.1 \%)$} \\
\hline ACR70 response at both week 24 and week 100 & & $10 / 14(71.4 \%)$ & $6 / 11(54.5 \%)$ \\
\hline DAS28-ESR ${ }^{* *}$ response at both week 24 and week 100 & & $55 / 67(82.1 \%)$ & $63 / 77(81.8 \%)$ \\
\hline \multicolumn{4}{|l|}{$\begin{array}{l}\text { DAS28-ESR }{ }^{* *} \text { response relative to dose escalation } \\
(50 \rightarrow 100 \mathrm{mg}) \text { among patients with ample dataף }\end{array}$} \\
\hline Previous to dose escalation & & \multicolumn{2}{|c|}{$17 / 35(48.6 \%)$} \\
\hline 12 weeks after dose escalation & & \multicolumn{2}{|c|}{$19 / 30(63.3 \%)$} \\
\hline 24 weeks after dose escalation & & \multicolumn{2}{|c|}{$21 / 29(72.4 \%)$} \\
\hline DAS28-CRP response at both week 24 and week 100 & & $55 / 71(77.5 \%)$ & $62 / 74(83.8 \%)$ \\
\hline \multicolumn{4}{|l|}{$\begin{array}{l}\text { DAS28-CRP response relative to dose escalation } \\
(50 \rightarrow 100 \mathrm{mg}) \text { among patients with ample data }\end{array}$} \\
\hline Previous to dose escalation & & \multicolumn{2}{|c|}{$63 / 113(55.8 \%)$} \\
\hline 12 weeks after dose escalation & & \multicolumn{2}{|c|}{$65 / 98(66.3 \%)$} \\
\hline 24 weeks after dose escalation & & \multicolumn{2}{|c|}{$46 / 66(69.7 \%)$} \\
\hline HAO improvement $\geq 0.25$ at both week 24 and week $100 \uparrow$ & & $55 / 68(80.9 \%)$ & $55 / 73(75.3 \%)$ \\
\hline \multicolumn{4}{|c|}{$\begin{array}{l}\text { Data presented are median (interquartile range) or number (\%) of randomised patients with sufficient data. Efficacy data pertaining to } \\
16 \text { patients }(5,6 \text { and } 5 \text { patients randomised to placebo, golimumab } 50 \mathrm{mg} \text { and golimumab } 100 \mathrm{mg} \text {, respectively) at site } 7465 \text { were } \\
\text { excluded due to violations at the study site identified during the sponsor's standard audit processes. } \\
\text { *Includes patients who EE at week } 16 \text { or crossed over at week } 24 \text { to receive golimumab } 50 \mathrm{mg} \text { or dose escalated after the week } 24 \\
\text { database lock to receive golimumab } 100 \mathrm{mg} \text {. } \\
\text { tIncludes patients who EE at week } 16 \text { or dose escalated after the week } 24 \text { database lock to receive golimumab } 100 \mathrm{mg} \text {. } \\
\text { łBy week } 160 \text {, only } 75,81 \text { and } 81 \text { patients had ACR response data in the placebo, golimumab } 50 \mathrm{mg} \text { and golimumab } 100 \mathrm{mg} \text { groups. } \\
\text { §Based on the week } 24 \text { responders who remained in the trial at week } 100 \text { for response rates at weeks } 52,100 \text { and } 160 \text {, respectively. } \\
\text { TAnalysis based on observed data. } \\
\text { **ESR determinations were not available for all patients at all time points; therefore, DAS28-ESR scores were determined in fewer patients. } \\
\text { ACR, American College of Rheumatology; CRP, C reactive protein; DAS, Disease Activity Score; EE, early escaped; ESR, erythrocyte } \\
\text { sedimentation rate; HAQ, Health Assessment Questionnaire. }\end{array}$} \\
\hline
\end{tabular}

who received golimumab $50 \mathrm{mg}(34 \%$, 46\% and 10\%, respectively) and $100 \mathrm{mg}(44 \%, 61 \%$ and $16 \%$, respectively) were significantly higher versus placebo-treated patients $(17 \%, 25 \%$ and $3 \%$, respectively; all $\mathrm{p}<0.05){ }^{1}$

The proportions of patients meeting the more stringent ACR50/70 response criteria appeared stable from week 52 to week 160 in all treatment groups (table 2). Similar findings were generally observed in $\geq 1$ golimumab group(s) for DAS28-ESR response, SDAI low disease activity (>3.3-11), SDAI remission and $\mathrm{HAQ}$ improvement (table 2). Thus, despite smaller numbers of patients in each group over time, response rates were generally sustained.

An important aspect of managing difficult-to-treat RA relates to maintenance of response. From week 24 to week 100, ACR20, DAS28 and $\geq 0.25$ unit $\mathrm{HAQ}$ responses were sustained in $70-73 \%, 78-84 \%$ and $75-81 \%$ of responding patients, respectively (table 3 ).

Among the 137 patients who dose escalated from $50 \mathrm{mg}$ to $100 \mathrm{mg}$ through week 160 (figure 1), within 12 weeks following dose escalation, ACR20 and ACR50 response rates increased and were generally maintained over the subsequent 88 weeks. A similar pattern was observed for DAS28 responses (table 3).
Golimumab efficacy was confirmed in patients receiving placebo $\rightarrow$ golimumab $50 \mathrm{mg}$ with or without further escalation to $100 \mathrm{mg}$. Clinical and functional response rates were similar to those demonstrated by patients who received golimumab since week 0 (tables 2 and 3).

\section{Adverse events}

AEs through week 24 of GO-AFTER have been reported. ${ }^{1}$ During the double-blind, placebo-controlled phase (weeks 0-16), 70\%, $61 \%$ and $73 \%$ of placebo, golimumab $50 \mathrm{mg}$ and golimumab 100 mg patients, respectively, experienced AEs. Infections (28\%, $27 \%$ and $25 \%$ ), serious AEs (7\%,5\% and $3 \%)$ and serious infections ( $2 \%, 2 \%$ and $1 \%$ ) were also consistent across treatment groups. More patients receiving golimumab $100 \mathrm{mg}(11 \%)$ had injectionsite reactions versus placebo (3\%) or golimumab $50 \mathrm{mg}(4 \%){ }^{1}{ }^{1}$

Largely because the GO-AFTER study design encompassed early escape and crossover to golimumab, average weeks of follow-up for LTE patients receiving golimumab $50 \mathrm{mg}$ and $100 \mathrm{mg}$ were 32 and 36 weeks at week 52, 48 and 65 weeks at week 100 and 60 and 102 weeks at week 160, respectively (table 4). Total patient-years of follow-up were 58, 319 and 645, respectively, for placebo, golimumab $50 \mathrm{mg}$ and golimumab $100 \mathrm{mg}$. 
Through week 52, when average weeks of follow-up were comparable for $50 \mathrm{mg}$ and $100 \mathrm{mg}, 76 \%$ of patients in each group experienced $\geq 1 \mathrm{AE}$, indicating no dose response. By week $160,81 \%$ (50 mg) and $90 \%$ (100 mg) of patients experienced $\geq 1$ $\mathrm{AE}$; respective incidences were $18 \%$ and $25 \%$ for serious AEs, $9 \%$ and $12 \%$ for discontinuation of study agent due to an $\mathrm{AE}$ and $5 \%$ and $9 \%$ for serious infections (table 4 ).

At week 160, the incidences (95\% CI) of serious infection were 8.66 (2.81 to 20.22), 4.70 (2.63 to 7.75) and 8.07 (6.02 to 10.58) per 100 patient-years (/100pt-years) of follow-up in patients randomised to placebo, golimumab $50 \mathrm{mg}$ and golimumab 100 $\mathrm{mg}$, respectively. For patients treated with golimumab $50 \mathrm{mg}$, the incidence/100pt-years ( $95 \% \mathrm{CI}$ ) of serious infections was not increased at week 52 (5.78 (2.77 to 10.63)) or week 100 (5.79 (3.24 to 9.95)) but was increased for golimumab $100 \mathrm{mg}$ at week 160 (8.07) relative to week 52 (6.10) and week 100 (6.63). However, the 95\% CI at week 100 (4.33 to 9.72) and week 160 (6.02 to 10.58) was contained within that for week 52 (3.05 to 10.92) (table 4). In the golimumab $100 \mathrm{mg}$ group, one patient had histoplasmosis and another had pulmonary tuberculosis. Further details of these opportunistic infections are provided in the online supplement.

The incidences $(95 \% \mathrm{CI})$ of death through week 160 were 1.73 (0.04 to 9.65), 0.00 (0.00 to 0.94$)$ and 0.62 (0.17 to 1.59)/100pt-years, respectively, for placebo, golimumab $50 \mathrm{mg}$ and golimumab $100 \mathrm{mg}$ (table 4). As reported previously, ${ }^{1}$ one placebo-treated patient died 6 months after enrolment. This 80 -year-old woman who did not EE and never received golimumab died from pancreatic cancer on day 177. Four additional patients, all women who received golimumab $100 \mathrm{mg}$, died between weeks 100 and 160. The reported causes (and times) of death were aggressive lymphoma (week 132), cardiovascular event (week 141), congestive heart failure (week 146) and pneumonia (week 158). Further details of patient deaths are provided in the online supplement.

The incidences (95\% CI) of malignancy at week 160 were 1.73 (0.04 to 9.66 ), 0.95 (0.20 to 2.77 ) and 2.04 (1.09 to 3.49)/100ptyears for placebo, golimumab $50 \mathrm{mg}$ and golimumab $100 \mathrm{mg}$, respectively. The largest difference between groups was observed for lymphoma, with incidences $(95 \% \mathrm{CI})$ of 0.00 (0.00 to 0.94$)$ for golimumab $50 \mathrm{mg}$ and 0.62 (0.17 to 1.59) for golimumab 100 $\mathrm{mg}$ (table 4). Among patients who received golimumab $100 \mathrm{mg}$, although the incidence (95\% CI) of malignancy/100pt-years was not increased from week 52 (1.12 (0.14 to 4.03)) to week 100 (0.77 (0.16 to 2.24)), it was higher at week 160 (2.04 (1.09 to 3.49$))$.

In an analysis comparing malignancy incidences with expected rates in the general US population per the SEER database (table 5 ), the $95 \%$ CI of SIRs for all treatment groups included unity. Thus, the incidence of all malignancies occurring among patients treated in this study does not differ significantly from those expected in the general US population. However, the $95 \%$ CI of the SIR for lymphoma in the golimumab $100 \mathrm{mg}$ group (5.55 to 52.15) did not include unity, suggesting that the lymphoma risk is increased with golimumab $100 \mathrm{mg}$ (table 5).

\section{DISCUSSION}

We previously reported on the use of subcutaneous golimumab in 461 patients with active RA who have previous experience with TNF antagonists in GO-AFTER, the first prospective, randomised, double-blind, placebo-controlled trial conducted in this patient population and the only such study with efficacy analysed according to randomised treatment groups. GO-AFTER has the longest planned follow-up period (5 years) among studies involving similar patient populations. Through week 24, golimumab $50 \mathrm{mg}$ and $100 \mathrm{mg}$ every 4 weeks yielded statistically significantly higher proportions of patients achieving clinical response and clinically meaningful improvements in physical function versus placebo and no unexpected safety concerns. ${ }^{1}$

The GO-AFTER LTE that began at week 24 is ongoing; we now report findings through week 160 , during which patients randomised to placebo crossed over to golimumab $50 \mathrm{mg}$ and then all patients receiving golimumab $50 \mathrm{mg}$ could have escalated from $50 \mathrm{mg}$ to $100 \mathrm{mg}$. Patients randomised to golimumab $100 \mathrm{mg}$ did not change treatment. Although comparative efficacy of golimumab $50 \mathrm{mg}$ and $100 \mathrm{mg}$ was similar at week 14, the golimumab dose was increased for $70 \%$ of eligible patients during the LTE, likely reflecting the refractory nature of disease in these patients who have previous experience with TNF inhibitors. Alternatively, the durability of clinical response to golimumab 50 mg may be less than that to golimumab $100 \mathrm{mg}$ in this patient population beyond 24 weeks or it could be that investigator discretion, rather than objective escalation criteria, allowed for the golimumab dose to be escalated despite achievement of an otherwise acceptable response.

The clinical response observed through week 24 was reproduced in the LTE within the placebo group, whereby similar ACR20/50/70 response rates were observed after switching to golimumab. Moreover, improvements in clinical signs/symptoms and physical function observed through week $24^{1}$ were maintained or enhanced through week 100 for most patients remaining in the trial. Importantly, $40-45 \%$ of patients who remained in the study sustained a DAS28-CRP score $<3.2$ through week 160. Golimumab dose escalation to $100 \mathrm{mg}$ during the LTE increased clinical response rates from before to after dose escalation, suggesting that patients who have previous experience with TNF inhibitors can benefit from golimumab dose increase(s).

The ability to draw firm conclusions from these dose escalation data, however, is limited by several factors, including the following: (1) relatively small numbers of patients were available for analysis at later follow-up visits, (2) the trial was neither designed nor powered to compare treatment groups beyond week 24 and (3) dose escalation was at the sole discretion of investigators. Nonetheless, taken together, the demonstration of longer-term efficacy provides additional support for the week 24 observation that patients who previously discontinued TNFantagonist treatment for any reason respond to golimumab.

Nearly $50 \%$ of randomised patients discontinued by week 160 , which is higher than discontinuation rates observed in other phase 3 golimumab trials, that is, $23 \%$ and $26 \%$ in GO-BEFORE and GO-FORWARD by week 160 (data not shown). This observation, as well as that of unsatisfactory therapeutic effect and AEs being common discontinuation reasons, is not surprising given that a total of $35 \%$ of these patients who have previous experience with TNF inhibitors ( $>65 \%$ of whom also have previous experience with synthetic DMARD, with 'synthetic DMARDs') discontinued such prior treatment due to intolerance (63/445 patients) or unsatisfactory therapeutic effect ( $92 / 445$ patients) and thus represent a population enriched with patients refractory to and/or intolerant of such treatment. Approximately two-thirds of patients continued pre-existing methotrexate treatment; the remaining patients received golimumab monotherapy. The length of the GO-AFTER LTE must also be considered when interpreting findings related to study agent discontinuation and efficacy (see above).

The short-term golimumab safety profile in patients who have previous experience with TNF inhibitors was similar to that for placebo throughout the 16-week placebo-controlled 
Table 4 Cumulative summary of golimumab safety through week 160 of the GO-AFTER trial

\begin{tabular}{|c|c|c|c|c|c|c|}
\hline & \multicolumn{2}{|c|}{ Week 52 golimumab } & \multicolumn{2}{|c|}{ Week 100 golimumab } & \multicolumn{2}{|c|}{ Week 160 golimumab } \\
\hline & $50 \mathrm{mg}$ & $100 \mathrm{mg}$ & $50 \mathrm{mg}$ & $100 \mathrm{mg}$ & $50 \mathrm{mg}$ & $100 \mathrm{mg}$ \\
\hline Number of treated patients* & 279 & 259 & 279 & 314 & 279 & 330 \\
\hline Average duration of follow-up (weeks) & 32.3 & 36.2 & 48.3 & 64.9 & 59.5 & 101.6 \\
\hline Average number of injections & 7.7 & 8.7 & 11.5 & 15.4 & 14.1 & 23.9 \\
\hline Average cumulative dose (mg) & 511.4 & 877.0 & 575.3 & 1539.5 & 705.9 & 2391.5 \\
\hline Patients with 1 or more AEs & $211(75.6 \%)$ & $198(76.4 \%)$ & $223(79.9 \%)$ & $259(82.5 \%)$ & $226(81.0 \%)$ & $296(89.7 \%)$ \\
\hline \multicolumn{7}{|l|}{ Common AEst } \\
\hline Upper respiratory tract infection & $30(10.8 \%)$ & $42(16.2 \%)$ & $43(15.4 \%)$ & $55(17.5 \%)$ & $44(15.8 \%)$ & $68(20.6 \%)$ \\
\hline $\mathrm{RA}$ & $30(10.8 \%)$ & $20(7.7 \%)$ & $34(12.2 \%)$ & $37(11.8 \%)$ & $39(14.0 \%)$ & $53(16.1 \%)$ \\
\hline Nasopharyngitis & $22(7.9 \%)$ & $28(10.8 \%)$ & $26(9.3 \%)$ & $36(11.5 \%)$ & $27(9.7 \%)$ & $45(13.6 \%)$ \\
\hline Sinusitis & $21(7.5 \%)$ & $17(6.6 \%)$ & $26(9.3 \%)$ & $30(9.6 \%)$ & $28(10.0 \%)$ & $41(12.4 \%)$ \\
\hline Diarrhoea & $15(5.4 \%)$ & $19(7.3 \%)$ & $16(5.7 \%)$ & $27(8.6 \%)$ & $17(6.1 \%)$ & $35(10.6 \%)$ \\
\hline \multicolumn{7}{|l|}{ Death $\ddagger$} \\
\hline Observed number of patients & $0(0.0 \%)$ & $0(0.0 \%)$ & $0(0.0 \%)$ & $0(0.0 \%)$ & $0(0.0 \%)$ & $4(1.2 \%)$ \\
\hline Incidence $(95 \% \mathrm{CI})$ per 100 pt-yrs & & & & & $\begin{array}{l}0.00 \\
(0.00 \text { to } 0.94)\end{array}$ & $\begin{array}{l}0.62 \\
(0.17 \text { to } 1.59)\end{array}$ \\
\hline Discontinuation due to $\mathrm{AE}(\mathrm{s})$ & $18(6.5 \%)$ & $8(3.1 \%)$ & $23(8.2 \%)$ & $16(5.1 \%)$ & $25(9.0 \%)$ & $38(11.5 \%)$ \\
\hline Serious AEs & $36(12.9 \%)$ & $20(7.7 \%)$ & $45(16.1 \%)$ & $52(16.6 \%)$ & $49(17.6 \%)$ & $83(25.2 \%)$ \\
\hline \multicolumn{7}{|l|}{ Common serious AEs§ } \\
\hline Pneumonia & $4(1.4 \%)$ & $2(0.8 \%)$ & $5(1.8 \%)$ & $4(1.3 \%)$ & $5(1.8 \%)$ & $8(2.4 \%)$ \\
\hline RA & $4(1.4 \%)$ & $0(0.0 \%)$ & $6(2.2 \%)$ & $3(1.0 \%)$ & $6(2.2 \%)$ & $7(2.1 \%)$ \\
\hline Osteoarthritis & $3(1.1 \%)$ & $0(0.0 \%)$ & $4(1.4 \%)$ & $4(1.3 \%)$ & $4(1.4 \%)$ & $5(1.5 \%)$ \\
\hline Arthralgia & $1(0.4 \%)$ & $1(0.4 \%)$ & $1(0.4 \%)$ & $3(1.0 \%)$ & $1(0.4 \%)$ & $3(0.9 \%)$ \\
\hline Infections & $118(42.3 \%)$ & $122(47.1 \%)$ & $140(50.2 \%)$ & $176(56.1 \%)$ & $149(53.4 \%)$ & $205(62.1 \%)$ \\
\hline \multicolumn{7}{|l|}{ Serious infections $\mathbb{I}$} \\
\hline Observed number of patients & $10(3.6 \%)$ & $8(3.1 \%)$ & $14(5.0 \%)$ & $18(5.7 \%)$ & $14(5.0 \%)$ & $30(9.1 \%)$ \\
\hline Observed number of serious infections & 10 & 11 & 15 & 26 & 15 & 52 \\
\hline Incidence $(95 \% \mathrm{CI})$ per100 pt-yrs & $\begin{array}{l}5.78 \\
(2.77 \text { to } 10.63)\end{array}$ & $\begin{array}{l}6.10 \\
(3.05 \text { to } 10.92)\end{array}$ & $\begin{array}{l}5.79 \\
\text { (3.24 to 9.95) }\end{array}$ & $\begin{array}{l}6.63 \\
(4.33 \text { to } 9.72)\end{array}$ & $\begin{array}{l}4.70 \\
(2.63 \text { to } 7.75)\end{array}$ & $\begin{array}{l}8.07 \\
(6.02 \text { to } 10.58)\end{array}$ \\
\hline \multicolumn{7}{|l|}{ Common serious infections ${ }^{* *}$} \\
\hline Pneumonia & $4(1.4 \%)$ & $2(0.8 \%)$ & $5(1.8 \%)$ & $4(1.3 \%)$ & $5(1.8 \%)$ & $8(2.4 \%)$ \\
\hline Urinary tract infection & $2(0.7 \%)$ & $0(0.0 \%)$ & $2(0.7 \%)$ & $2(0.6 \%)$ & $2(0.7 \%)$ & $3(0.9 \%)$ \\
\hline Sepsis & $0(0.0 \%)$ & $1(0.4 \%)$ & $0(0.0 \%)$ & $2(0.6 \%)$ & $0(0.0 \%)$ & $4(1.2 \%)$ \\
\hline Diverticulitis & $0(0.0 \%)$ & $1(0.4 \%)$ & $0(0.0 \%)$ & $2(0.6 \%)$ & $0(0.0 \%)$ & $3(0.9 \%)$ \\
\hline Abdominal abscess & $0(0.0 \%)$ & $0(0.0 \%)$ & $0(0.0 \%)$ & $0(0.0 \%)$ & $0(0.0 \%)$ & $2(0.6 \%)$ \\
\hline Cellulitis & $0(0.0 \%)$ & $0(0.0 \%)$ & $1(0.4 \%)$ & $1(0.3 \%)$ & $1(0.4 \%)$ & $1(0.3 \%)$ \\
\hline Gastroenteritis & $1(0.4 \%)$ & $2(0.8 \%)$ & $0(0.0 \%)$ & $2(0.6 \%)$ & $0(0.0 \%)$ & $2(0.6 \%)$ \\
\hline Herpes zoster & $0(0.0 \%)$ & $0(0.0 \%)$ & $0(0.0 \%)$ & $0(0.0 \%)$ & $0(0.0 \%)$ & $2(0.6 \%)$ \\
\hline Infection & $0(0.0 \%)$ & $0(0.0 \%)$ & $0(0.0 \%)$ & $1(0.3 \%)$ & $0(0.0 \%)$ & $2(0.6 \%)$ \\
\hline Urosepsis & $2(0.7 \%)$ & $0(0.0 \%)$ & $2(0.7 \%)$ & $0(0.0 \%)$ & $2(0.7 \%)$ & $0(0.0 \%)$ \\
\hline \multicolumn{7}{|l|}{ All malignancies $\ddagger$} \\
\hline Observed number of patients & 1 & 2 & 2 & 3 & 3 & 13 \\
\hline Incidence $(95 \%$ Cl) per 100 pt-yrs & 0.58 (0.01 to 3.24$)$ & $1.12(0.14$ to 4.03$)$ & $0.77(0.09$ to 2.80$)$ & 0.77 (0.16 to 2.24) & 0.95 (0.20 to 2.77 ) & 2.04 (1.09 to 3.49 ) \\
\hline \multicolumn{7}{|l|}{ Lymphoma } \\
\hline Observed number of patients & 0 & 1 & 0 & 1 & 0 & 4 \\
\hline Incidence $(95 \%$ Cl) per 100 pt-yrs & $0.00(0.00$ to 1.74$)$ & $0.56(0.01$ to 3.11$)$ & $0.00(0.00$ to 1.16$)$ & $0.26(0.01$ to 1.42$)$ & $0.00(0.00$ to 0.94$)$ & $0.62(0.17$ to 1.59$)$ \\
\hline \multicolumn{7}{|l|}{ Nonmelanoma skin cancers } \\
\hline Observed number of patients & 1 & 0 & 1 & 1 & 1 & 5 \\
\hline Incidence (95\% Cl) per 100 pt-yrs & $0.58(0.01$ to 3.24$)$ & $0.00(0.00$ to 1.67$)$ & $0.39(0.01$ to 2.16$)$ & $0.26(0.01$ to 1.42$)$ & $0.31(0.01$ to 1.75$)$ & $0.78(0.25$ to 1.82$)$ \\
\hline \multicolumn{7}{|l|}{ Other malignancies $\ddagger$} \\
\hline Observed number of patients & 0 & 1 & 1 & 1 & 2 & 4 \\
\hline Incidence (95\% Cl) per 100 pt-yrs & $0.00(0.00$ to 1.74$)$ & $0.56(0.01$ to 3.11$)$ & $0.39(0.01$ to 2.15$)$ & $0.26(0.01$ to 1.42$)$ & 0.63 (0.08 to 2.27$)$ & $0.62(0.17$ to 1.59$)$ \\
\hline \multicolumn{7}{|l|}{ Golimumab injection-site reactions } \\
\hline Patients & $20(7.2 \%)$ & $23(8.9 \%)$ & $20(7.2 \%)$ & $30(9.6 \%)$ & $21(7.5 \%)$ & $31(9.4 \%)$ \\
\hline Injections & $26 / 2157(1.2 \%)$ & $51 / 2260(2.3 \%)$ & $29 / 3210(0.9 \%)$ & $73 / 4835(1.5 \%)$ & $30 / 3939(0.8 \%)$ & $82 / 7893(1.0 \%)$ \\
\hline
\end{tabular}

Data presented are number (\%) of patients unless noted otherwise noted.

*Patients could appear in more than one column.

tOccurring in $\geq 10 \%$ of patients in either golimumab dose group.

$\ddagger$ As previously reported by Smolen and colleagues, ${ }^{1}$ an additional patient in the placebo group who did not meet the early escape criteria died of pancreatic cancer. The resulting

incidence is $1.73(95 \% \mathrm{Cl} 0.04$ to 9.65$)$ and 1.73 (95\% $\mathrm{Cl} 0.04$ to 9.66$)$ per 100 pt-yrs of follow-up for death and other/all malignancies, respectively.

$\S 0$ ccurring in $\geq 1 \%$ of patients in either golimumab dose group.

ISerious infections were observed in $5(3.2 \%)$ patients through a total of 58 pt-years of follow-up pertaining to receipt of placebo, equating to an incidence of 8.66 (95\% Cl 28.1 to

20.22) per 100 pt-yrs of follow-up.

**0ccurring in $\geq 2$ patients overall.

$A E$, adverse event; pt-years, patient-years of follow-up; RA, rheumatoid arthritis. 
Table 5 Number of patients with one or more malignancies through week 160 compared with the expected number of malignancies from the general US population according to the SEER database

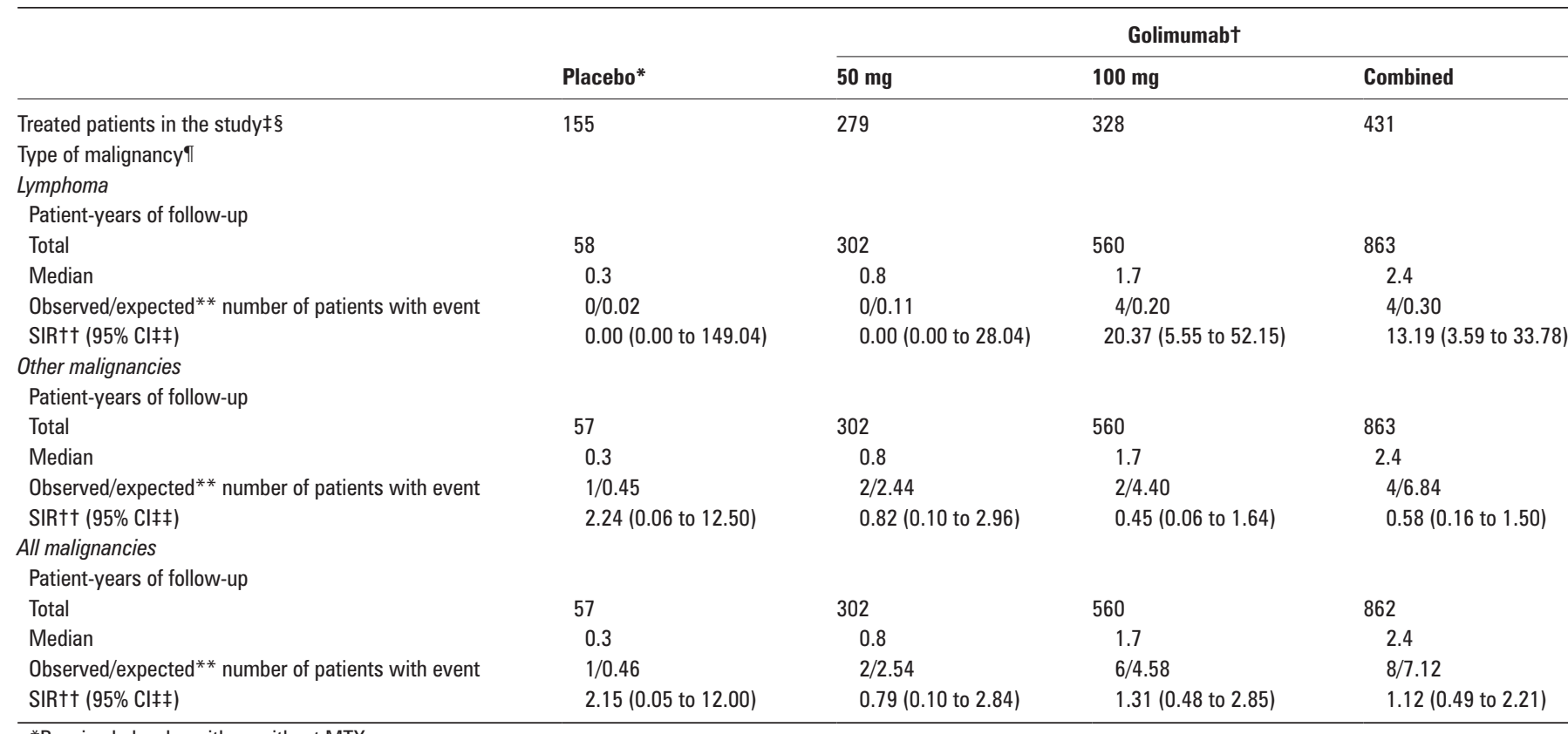

*Received placebo with or without MTX.

†Received golimumab with or without MTX. Subcutaneous injections were administered every 4 weeks.

$\ddagger$ Patients may appear in more than one column.

§Through 12 August 2009.

IIncludes patients with malignancies (excluding nonmelanoma skin cancers, which are not included in the SEER database) during the study.

***The expected number of patients with malignancies is based on the SEER database, ${ }^{13}$ adjusted for age, gender and race.

T†SIR is the observed number of patients with malignancy divided by expected number of patients with malignancy.

$\ddagger \ddagger C l$ based on an exact method.

MTX, methotrexate; SEER, Surveillance, Epidemiology and End Results (database); SIR, standardised incidence ratio.

period. ${ }^{1}$ Through week 160 , the length of follow-up for the placebo-controlled phase was 16 weeks versus 60 and 102 weeks for golimumab $50 \mathrm{mg}$ and $100 \mathrm{mg}$, respectively. Thus, the higher incidences observed for specific AE categories through week 160 (table 4) relative to observations through week $16^{1}$ were not unexpected given follow-up periods almost 4 times $(50 \mathrm{mg}$ ) and more than 6 times $(100 \mathrm{mg})$ the length of placebo-controlled follow-up. Also through week 160, patients treated with golimumab $100 \mathrm{mg}$ received an average cumulative dose $>3$ times that for golimumab $50 \mathrm{mg}$ (table 4), yielding an overall follow-up of golimumab $100 \mathrm{mg}$ (645 pt-years) 10 times that for placebo (58 pt-years) and 2 times that for golimumab $50 \mathrm{mg}$ (319 pt-yrs). These imbalances in exposure/follow-up were largely driven by the fact that, while $33 \%$ of enrolled patients were randomised to golimumab $100 \mathrm{mg}$, by week $160,81 \%$ of the remaining patients were receiving golimumab $100 \mathrm{mg}$. When adjusted for length of patient follow-up, however, the incidences of serious infection, malignancy/lymphoma and death were higher in the $100 \mathrm{mg}$ group, indicating a potential effect of golimumab dose. A similar pattern of a higher incidence of certain AEs with higher drug exposure was observed in the START trial of infliximab in patients with RA. In that trial, high serum infliximab concentrations during the induction regimen of $10 \mathrm{mg} / \mathrm{kg}$ given at weeks 0,2 and 6 may have been associated with an increased risk of serious infections during the first 22 weeks of the trial. During the maintenance period, when infusions were administered every 8 weeks and peak serum infliximab concentrations may not have reached the same level as they did during the induction period, the risk of serious infection was reduced and consistent with that observed with lower infliximab doses. ${ }^{14}$
B cell lymphomas were the most common of lymphoma cases (supplementary table 1), which is consistent with that observed in patients with RA. ${ }^{15}$ Irrespective of TNF-antagonist treatment, patients with RA have an increased lymphoma risk versus the general population; ${ }^{16}$ this risk increases with disease duration and severity. ${ }^{15}$ 17-19 GO-AFTER patients, with average disease durations of 10.6-12.4 years and previous receipt of anti-TNF treatment (indicating active refractory disease), represent an RA cohort consistent with increased lymphoma risk. ${ }^{15}$

The potential contribution of anti-TNF treatment to lymphoma remains an area of debate. Although an increased risk has been suggested with anti-TNF treatment, ${ }^{20}$ an alternative hypothesis asserts that lymphoma risk is actually related to RA severity and may decrease with control of chronic inflammation via disease-modifying treatment. ${ }^{18} 21$ Consistent with this hypothesis, Askling and colleagues ${ }^{22}$ observed no overall elevation of cancer risk and no increase with increasing duration of anti-TNF treatment in their evaluation of 6366 patients with RA (25 693 pt-years of follow-up). Data supporting the possible relationship between clinical status and lymphoma have also been reported by Wolfe and Michaud in their prospective evaluation of 19562 patients (89 710 pt-years) enrolled in a longitudinal RA registry. ${ }^{23} 24$ However, because patients with the worst clinical status appeared to receive anti-TNF treatment preferentially, the authors were limited in their ability to establish causal relationships between RA treatment and lymphoma. ${ }^{23} 24$

At baseline, the four GO-AFTER patients diagnosed as having lymphoma had disease durations ranging from 5 to 31 years and substantial tender/swollen joint counts; three of the four patients also had baseline DAS28 and/or SDAI scores falling within the 
higher quartiles of scores observed across all patients, and follow-up scores at the time of lymphoma diagnosis were largely consistent with those documented at baseline, with the exception of one patient whose DAS28 and SDAI scores improved from a higher to a lower quartile from baseline to that time. Further discussion of these four patients with lymphoma is provided as online supplemental text.

In addition to the study limitations discussed above, the ability to evaluate effects of golimumab dose on safety was also limited by the GO-AFTER study design that allowed for dose escalation and yielded markedly differing lengths of follow-up for golimumab 50 mg (319 pt-years) versus 100 mg (645 pt-years).

Taken together with findings previously reported through week 24 of the GO-AFTER trial, ${ }^{1}$ these longer-term findings through 3 years support the efficacy of golimumab in patients with active RA previously treated with TNF antagonist(s); definitive conclusions regarding long-term safety will require further monitoring.

Acknowledgements The authors thank Mahboob U Rahman, MD (a former Janssen employee who is now an employee of Pfizer Inc.), for his work pertaining to the GO-AFTER clinical trial and Michelle L Perate, MS, and Mary H Whitman, PhD, of Janssen Biotech Inc. for their excellent assistance with manuscript preparation and submission.

Funding This study was sponsored by Janssen Research \& Development and Merck/ Schering-Plough Research Institute.

Competing interests JS Smolen has received research grant support from Abbott, BMS, MSD, Pfizer, Roche and UCB and consultation and/or speaking honoraria from Abbott, Astra-Zeneca, BMS, Celgene, Glaxo, Janssen, MSD, Novo-Nordisk, Pfizer, Roche, Sanofi-Aventis and UCB. J Kay has received research funding paid to the University of Massachusetts Medical School from Bristol Myers Squibb Co., F. Hoffmann-La Roche Ltd. and Sanofi-Aventis and consulting income from Bristol Myers Squibb Co., Crescendo BioScience Inc., Eisai Co. Ltd., Janssen, Johnson \& Johnson, Mallinckrodt Inc., NovoNordisk Inc., Pfizer Inc. and UCB S.A. R Landewé has received research grant support from Abbott, Pfizer, Roche and UCB and consultation and/or speaking honoraria from Abbott, Astra-Zeneca, BMS, Glaxo, Janssen, MSD, Pfizer, Roche and UCB. EL Matteson has received research grant support and consultation honoraria from Janssen. N Gaylis has received research grant support and consultation and/or speaking honoraria from Janssen/Johnson \& Johnson and serves as Medical Director Rheumatology Division —Cardinal Health. J Wollenhaupt has received consultation and/or speaking honoraria from Abbott, Amgen, BMS, Chugai, MSD, Medac, Pfizer, Roche, Sanofi-Aventis and UCB. FT Murphy has received speaking honoraria from Abbott Immunology and Janssen. Y Zhou, EC Hsia and MK Doyle are employees of Janssen Research and Development.

Ethics approval All patients provided written informed consent, and the protocol was approved by each institution's human subjects ethical review board.

Provenance and peer review Not commissioned; externally peer reviewed.

\section{REFERENCES}

1. Smolen JS, Kay J, Doyle MK, et al. Golimumab in patients with active rheumatoid arthritis after treatment with tumour necrosis factor alpha inhibitors (GO-AFTER study): a multicentre, randomised, double-blind, placebo-controlled, phase III trial. Lancet 2009;374:210-21.

2. Arnett FC, Edworthy SM, Bloch DA, et al. The American Rheumatism Association 1987 revised criteria for the classification of rheumatoid arthritis. Arthritis Rheum 1988;31:315-24.

3. Felson DT, Anderson JJ, Boers M, et al. American College of Rheumatology. Preliminary definition of improvement in rheumatoid arthritis. Arthritis Rheum 1995;38:727-35.
4. Prevoo ML, van't Hof MA, Kuper HH, et al. Modified disease activity scores that include twenty-eight-joint counts. Development and validation in a prospective Iongitudinal study of patients with rheumatoid arthritis. Arthritis Rheum 1995;38:44-8.

5. Aletaha D, Landewe R, Karonitsch T, et al. Reporting disease activity in clinical trials of patients with rheumatoid arthritis: EULAR/ACR collaborative recommendations. Ann Rheum Dis 2008;67:1360-4.

6. van Riel PL, van Gestel AM. Clinical outcome measures in rheumatoid arthritis. Ann Rheum Dis 2000;59(Suppl 1):i28-31.

7. Wells G, Becker JC, Teng J, et al. Validation of the 28-joint Disease Activity Score (DAS28) and European League Against Rheumatism response criteria based on C-reactive protein against disease progression in patients with rheumatoid arthritis, and comparison with the DAS28 based on erythrocyte sedimentation rate. Ann Rheum Dis 2009;68:954-60.

8. Smolen JS, Breedveld FC, Schiff MH, et al. A simplified disease activity index for rheumatoid arthritis for use in clinical practice. Rheumatology (Oxford) 2003;42:244-57

9. Felson DT, Smolen JS, Wells G, et al. American College of Rheumatology/European League against Rheumatism provisional definition of remission in rheumatoid arthritis for clinical trials. Ann Rheum Dis 2011;70:404-13.

10. Fries JF, Spitz P, Kraines RG, et al. Measurement of patient outcome in arthritis. Arthritis Rheum 1980:23:137-45.

11. Wells GA, Tugwell P, Kraag GR, et al. Minimum important difference between patients with rheumatoid arthritis: the patient's perspective. J Rheumatol 1993;20:557-60

12. Buch MH, Aletaha D, Emery P, et al. Reporting of long-term extension studies: lack of consistency calls for consensus. Ann Rheum Dis 2011;70:886-90.

13. National Cancer Institute. The Surveillance, Epidemiology, and End Results (SEER), 2004. URL: http://seer.cancer.gov. (accessed 27 Feb 2012).

14. Westhovens R, Yocum D, Han J, et al. The safety of infliximab, combined with background treatments, among patients with rheumatoid arthritis and various comorbidities: a large, randomized, placebo-controlled trial. Arthritis Rheum 2006:54:1075-86.

15. Hansen A, Lipsky PE, Dörner T. B-cell lymphoproliferation in chronic inflammatory rheumatic diseases. Nat Clin Pract Rheumatol 2007:3:561-9.

16. Smitten AL, Simon TA, Hochberg MC, et al. A meta-analysis of the incidence of malignancy in adult patients with rheumatoid arthritis. Arthritis Res Ther 2008;10:R45

17. Baecklund $\mathbf{E}$, Ekbom A, Sparén $P$, et al. Disease activity and risk of lymphoma in patients with rheumatoid arthritis: nested case-control study. BMJ 1998;317:180-1.

18. Baecklund $\mathbf{E}$, lliadou A, Askling J, et al. Association of chronic inflammation, not its treatment, with increased lymphoma risk in rheumatoid arthritis. Arthritis Rheum 2006;54:692-701

19. Geborek P, Bladström A, Turesson C, et al. Tumour necrosis factor blockers do not increase overall tumour risk in patients with rheumatoid arthritis, but may be associated with an increased risk of lymphomas. Ann Rheum Dis 2005;64:699-703

20. Mariette $\mathbf{X}$, Tubach $\mathrm{F}$, Bagheri $\mathrm{H}$, et al. Lymphoma in patients treated with anti-TNF: results of the 3-year prospective French RATIO registry. Ann Rheum Dis 2010;69:400-8.

21. Williams GM. Antitumor necrosis factor-alpha therapy and potential cancer inhibition. Eur J Cancer Prev 2008;17:169-77.

22. Askling J, van Vollenhoven RF, Granath $\mathrm{F}$, et al. Cancer risk in patients with rheumatoid arthritis treated with anti-tumor necrosis factor alpha therapies: does the risk change with the time since start of treatment? Arthritis Rheum 2009;60:3180-9.

23. Wolfe $\mathbf{F}$, Michaud K. Lymphoma in rheumatoid arthritis: the effect of methotrexate and anti-tumor necrosis factor therapy in 18,572 patients. Arthritis Rheum 2004:50:1740-51.

24. Wolfe F, Michaud K. The effect of methotrexate and anti-tumor necrosis factor therapy on the risk of lymphoma in rheumatoid arthritis in 19,562 patients during 89,710 person-years of observation. Arthritis Rheum 2007:56:1433-9.

25. Rosselet A, Vu DH, Meylan P, et al. Associations of serum EBV DNA and gammopathy with post-transplant lymphoproliferative disease. Clin Transplant 2009;23:74-82. 